\title{
Impact of COVID-19 on hospital hand hygiene performance: a multicentre observational study using group electronic monitoring
}

\author{
Victoria Williams MPH, Adam Kovacs-Litman MD, Matthew P. Muller MD PhD, Susy Hota MD MSc, \\ Jeff E. Powis MD MSc, Daniel R. Ricciuto MD, Dominik Mertz MD MSc, Kevin Katz MD, \\ Lucas Castellani MD, Alex Kiss PhD, Amber Linkenheld-Struk MLT, Jerome A. Leis MD MSc
}

Abstract

Background: Reliable reports on hand hygiene performance throughout the COVID-19 pandemic are lacking as most hospitals continue to rely on direct observation to measure this quality indicator. Using group electronic hand hygiene monitoring, we sought to assess the impact of COVID-19 on adherence to hand hygiene.

Methods: Across 12 Ontario hospitals (5 university and 7 community teaching hospitals), a group electronic hand hygiene monitoring system was installed before the pandemic to provide continuous measurement of hand hygiene adherence across 978 ward and 367 critical care beds. We performed an interrupted time-series study of institutional hand hygiene adherence in association with a COVID-19 inpatient census and the Ontario daily count of COVID-19 cases during a baseline period (Nov. 1, 2019, to Feb. 29, 2020), the pre-peak period of the first wave of the pandemic (Mar. 1 to Apr. 24, 2020), and the post-peak period of the first wave (Apr. 25 to July 5, 2020). We used a Poisson regression model to assess the association between the hospital COVID-19 census and institutional hand hygiene adherence while adjusting for the correlation within inpatient units.

Results: At baseline, the rate of hand hygiene adherence was 46.0\% (6325401 of 13750968 opportunities) and this improved beginning in March 2020 to a daily peak of 79.3\% (66640 of 84026 opportunities) on Mar. 30, 2020. Each patient admitted with COVID-19 was associated with improved hand hygiene adherence (incidence rate ratio [IRR] 1.0621, 95\% confidence interval [Cl] 1.0619-1.0623). Increasing Ontario daily case count was similarly associated with improved hand hygiene (IRR $1.0026,95 \% \mathrm{CI}$ 1.0021-1.0032). After peak COVID-19 community and inpatient numbers, hand hygiene adherence declined and returned to baseline.

Interpretation: The first wave of the COVID-19 pandemic was associated with significant improvement in hand hygiene adherence, measured using a group electronic monitoring system. Future research should seek to determine whether strategies that focus on health care worker perception of personal risk can achieve sustainable improvements in hand hygiene performance.

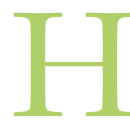

and hygiene is a routine practice that should be applied universally in the provision of health care to prevent transmission of infections, including SARS-CoV-2., ${ }^{1,2}$ Despite its importance, reports on hand hygiene performance throughout the pandemic are lacking as most hospitals continue to rely on direct observation to measure this quality indicator, a method that is widely recognized to be inaccurate because of sampling and observer biases. ${ }^{3-5}$

A single inpatient unit in France, using an automated monitoring system, observed small improvements in hand hygiene on room entry and exit during the COVID-19 pandemic. ${ }^{6}$ Similarly, a single-centre study in a University of Chicago hospital that used a different automated system measured nearly 90\% hand hygiene adherence on dedicated COVID-19 units, but employee practices reverted to baseline after the first wave of the pandemic.?
Our hospital quality improvement network, Hand Hygiene Improvement Preventing and Controlling Transmission (HH-IMPACT) is composed of 12 Ontario university and community teaching hospitals; it introduced a group electronic hand hygiene monitoring system before the COVID-19

Competing interests: Susy Hota reports funding from Finch Therapeutics Group and participation with the board of directors of the Association for Medical Microbiology and Infectious Diseases Canada, outside the submitted work. Jerome Leis reports payment for expert testimony for the Ontario Hospital Association and the Ontario Ministry of Attorney General, outside the submitted work. No other competing interests were declared.

This article has been peer reviewed.

Correspondence to: Jerome Leis, jerome.leis@sunnybrook.ca CMAJ Open 2021 December 14. DOI:10.9778/cmajo.20210072 
pandemic. ${ }^{8,9}$ Equipped with this more accurate method of measuring hand hygiene performance, we sought to assess the impact of the COVID-19 pandemic on hand hygiene adherence. We hypothesized that the global spread of SARS-CoV-2, coupled with widespread public awareness of COVID-19 prevention strategies, would augment hand hygiene practices. We performed an interrupted time-series study to assess the impact of both provincial COVID-19 case counts and hospital-level COVID-19 admissions on hand hygiene adherence.

\section{Methods}

\section{Study design and setting}

We conducted a multicentre, observational, interrupted time-series study in accordance with the Strengthening the Reporting of Observational Studies in Epidemiology (STROBE) principles. ${ }^{10} \mathrm{HH}-\mathrm{IMPACT}$ is a hand hygiene quality improvement network of acute care hospitals in Ontario, Canada. This network introduced a group electronic hand hygiene monitoring system for 1345 inpatient beds (978 ward and 367 critical care) across 51 inpatient units (31 wards and 20 critical care units) spanning 12 acute care hospitals (5 university and 7 community teaching hospitals). One site had no critical beds, and 6 sites had no electronically monitored ward beds.

The study time period was Nov. 1, 2019, to July 5, 2020, divided into the following 3 time periods for analytical purposes: the baseline period (Nov. 1, 2019, to Feb. 29, 2020); the pre-peak period of the first wave of COVID-19 (Mar. 1 to Apr. 24, 2020) and the post-peak period of the first wave (Apr. 25 to July 5, 2020). Study sites were in southeastern Ontario, southwestern Ontario and northern Ontario. All 31 wards received feedback on hand hygiene performance throughout the entire study period, and the 20 critical care units received feedback from Jan. 6, 2020, onward. ${ }^{9}$ This feedback was provided in the form of automated email reports, posters and in-person huddles on the unit.,

\section{Exposure and outcome variables}

We used 2 separate exposure variables. The first exposure variable was the daily hospitalized COVID-19 census, which included all patients admitted to HH-IMPACT hospitals with laboratory-confirmed SARS-CoV-2 infections requiring additional precautions, counted at the start of each day. The second exposure variable was Ontario's daily number of new laboratory-confirmed SARS-CoV-2 infections in the province.

The outcome variable was overall hand hygiene adherence, calculated as the proportion of all hand hygiene events divided by hand hygiene opportunities for each electronically monitored bed at each hospital site.

\section{Data sources}

We measured hand hygiene adherence using the DebMed Hand Hygiene Monitoring System (DebMed SC Johnson Professional), which was installed on all alcohol hand sanitizer and sink soap dispensers inside and outside each patient room between 2017 and 2019. This system measures $100 \%$ of all hand sanitizer and soap dispenser activations via a signal to a wireless hub. Total dispenser activations at a unit level are divided by a previously validated estimate of the number of hand hygiene opportunities per patient-hour, multiplied by the hourly census of patients on the unit to derive an estimate of hand hygiene adherence. $8,9,11$ Hand hygiene data were collected and stored on a secure server, and were accessible via an online dashboard for all units throughout the study period. We ended the study in July 2020, when a pandemic-related shortage in hand sanitizer occurred.

Each hospital's infection prevention and control team prospectively recorded the daily number of hospitalized patients with COVID-19. We calculated COVID-19 bed days based on the number of days that each patient with a laboratoryconfirmed SARS-CoV-2 infection remained in additional precautions. We obtained Ontario's daily case count from publicly available data published by Public Health Ontario. ${ }^{12}$

\section{Statistical analysis}

We compared aggregate peak and nadir hand hygiene performance over time in association with the COVID-19 hospital census and Ontario's daily COVID-19 case count. We used a zero-inflated Poisson regression model to assess the association between the hospital COVID-19 census and institutional hand hygiene adherence. Using segmented regression analysis, we performed a hospital-based analysis across the 3 time periods (study start to first COVID-19 inpatient in March 2020, first COVID-19 inpatient to peak COVID-19 inpatient census, and peak COVID-19 inpatient census to study end). The model accounted for clustering within units and incorporated an autoregressive component for days within a unit to capture the serial nature of the data. Results were expressed as incidence rate ratios (IRRs) and their associated 95\% confidence intervals (CIs).

We repeated analyses using a date-based analysis of 3 time periods (baseline period from Nov. 1, 2019, to Feb. 29, 2020; the pre-peak period of the first wave from Mar. 1 to Apr. 24, 2020; and the post-peak period of the first wave from Apr. 25, 2020, to July 5, 2020). We created separate models for both exposure variables. For each exposure variable, we created a group variable with an interaction term between the 2 variables to assess statistical differences between each predictor in relation to the outcome of hand hygiene adherence.

\section{Ethics approval}

This study was approved by or was granted a quality improvement designation by the research ethics board at each of the participating sites.

\section{Results}

Table 1 provides baseline characteristics of the 12 acute care hospitals. Table 2 provides the hand hygiene adherence across the 3 study periods by hospital site. Admission of patients with COVID-19 varied across hospital sites, with a maximum daily census ranging from 3 to 84 inpatients. One site did not have any admissions of patients confirmed positive for SARS-CoV-2. 


\begin{tabular}{|c|c|c|c|c|c|c|}
\hline Hospital & $\begin{array}{l}\text { Hospital } \\
\text { type }\end{array}$ & $\begin{array}{l}\text { No. of beds } \\
\text { monitored }\end{array}$ & $\begin{array}{l}\text { No. of critical } \\
\text { care units }\end{array}$ & $\begin{array}{l}\text { No. of critical } \\
\text { care beds }\end{array}$ & $\begin{array}{l}\text { No. of } \\
\text { wards }\end{array}$ & $\begin{array}{c}\text { No. of } \\
\text { ward beds }\end{array}$ \\
\hline 1 & University & 391 & 6 & 83 & 9 & 308 \\
\hline 2 & University & 230 & 2 & 45 & 7 & 185 \\
\hline 3 & University & 56 & 3 & 56 & 0 & 0 \\
\hline 4 & University & 26 & 2 & 26 & 0 & 0 \\
\hline 5 & University & 30 & 1 & 30 & 0 & 0 \\
\hline 6 & Community & 120 & 1 & 20 & 3 & 100 \\
\hline 7 & Community & 166 & 1 & 27 & 4 & 139 \\
\hline 8 & Community & 29 & 0 & 0 & 1 & 29 \\
\hline 9 & Community & 235 & 1 & 18 & 7 & 217 \\
\hline 10 & Community & 24 & 1 & 24 & 0 & 0 \\
\hline 11 & Community & 24 & 1 & 24 & 0 & 0 \\
\hline 12 & Community & 14 & 1 & 14 & 0 & 0 \\
\hline
\end{tabular}

\begin{tabular}{|c|c|c|c|c|c|c|c|c|}
\hline \multirow[b]{2}{*}{ Hospital } & \multicolumn{2}{|c|}{$\begin{array}{c}\text { Baseline } \\
\text { (Nov. 1, 2019-Feb. 29, 2020) }\end{array}$} & \multicolumn{2}{|c|}{$\begin{array}{c}\text { Pre-peak } \\
\text { (Mar. 1-Apr. 24, 2020) }\end{array}$} & \multicolumn{2}{|c|}{$\begin{array}{c}\text { Post-peak } \\
\text { (Apr. 25-July 5, 2020) }\end{array}$} & \multirow[b]{2}{*}{$\begin{array}{c}\text { IRR } \\
(95 \% \mathrm{Cl})^{*}\end{array}$} & \multirow{2}{*}{$\begin{array}{c}\text { Patient-days } \\
\text { (maximum } \\
\text { bed census) } \dagger\end{array}$} \\
\hline & $\begin{array}{c}\text { No. of } \mathrm{HH} \\
\text { opportunities }\end{array}$ & $\begin{array}{l}\text { No. }(\%) \text { of } \\
\text { HH events }\end{array}$ & $\begin{array}{c}\text { No. of } \mathrm{HH} \\
\text { opportunities }\end{array}$ & $\begin{array}{l}\text { No. }(\%) \text { of } \\
\text { HH events }\end{array}$ & $\begin{array}{c}\text { No. of } \mathrm{HH} \\
\text { opportunities }\end{array}$ & $\begin{array}{l}\text { No. }(\%) \text { of } \\
\text { HH events }\end{array}$ & & \\
\hline 1 & 3784445 & $\begin{array}{c}2043422 \\
(54.0)\end{array}$ & 1335290 & $\begin{array}{c}1057932 \\
(79.2)\end{array}$ & 1972242 & $\begin{array}{c}1422267 \\
(72.1)\end{array}$ & $\begin{array}{c}1.467 \\
(1.464-1.471)\end{array}$ & $\begin{array}{l}1250 \\
(24)\end{array}$ \\
\hline 2 & 1756196 & $\begin{array}{c}770695 \\
(43.9)\end{array}$ & 736718 & $\begin{array}{c}424965 \\
(57.7)\end{array}$ & 1093721 & $\begin{array}{c}472466 \\
(43.2)\end{array}$ & $\begin{array}{c}1.314 \\
(1.310-1.319)\end{array}$ & $\begin{array}{l}846 \\
(36)\end{array}$ \\
\hline 3 & 991155 & $\begin{array}{c}226530 \\
(22.9)\end{array}$ & 364609 & $\begin{array}{c}161631 \\
(44.3)\end{array}$ & 537770 & $\begin{array}{c}170035 \\
(31.6)\end{array}$ & $\begin{array}{c}1.940 \\
(1.927-1.952)\end{array}$ & $\begin{array}{l}1427 \\
(34) \\
\end{array}$ \\
\hline 4 & 565189 & $\begin{array}{c}131557 \\
(23.3)\end{array}$ & 176885 & $\begin{array}{l}79958 \\
(45.2)\end{array}$ & 245002 & $\begin{array}{c}76319 \\
(31.2)\end{array}$ & $\begin{array}{c}1.942 \\
(1.925-1.959)\end{array}$ & $\begin{array}{l}215 \\
(11)\end{array}$ \\
\hline 5 & 566904 & $\begin{array}{c}255363 \\
(45.0)\end{array}$ & 262389 & $\begin{array}{c}173352 \\
(66.1)\end{array}$ & 409390 & $\begin{array}{c}239565 \\
(58.5)\end{array}$ & $\begin{array}{c}1.467 \\
(1.458-1.476)\end{array}$ & $\begin{array}{c}4588 \\
(84)\end{array}$ \\
\hline 6 & 1186495 & $\begin{array}{c}492062 \\
(41.5)\end{array}$ & 438997 & $\begin{array}{c}304884 \\
(69.5)\end{array}$ & 592434 & $\begin{array}{c}345649 \\
(58.3)\end{array}$ & $\begin{array}{c}1.675 \\
(1.667-1.682)\end{array}$ & $\begin{array}{c}2268 \\
(47)\end{array}$ \\
\hline 7 & 1616146 & $\begin{array}{c}808862 \\
(50.0)\end{array}$ & 647672 & $\begin{array}{c}448435 \\
(69.2)\end{array}$ & 783123 & $\begin{array}{c}501270 \\
(64.0)\end{array}$ & $\begin{array}{c}1.383 \\
(1.378-1.388)\end{array}$ & $\begin{array}{l}868 \\
(21)\end{array}$ \\
\hline 8 & 220249 & $\begin{array}{c}108022 \\
(49.0)\end{array}$ & 77008 & $\begin{array}{l}60489 \\
(78.5)\end{array}$ & 56919 & $\begin{array}{l}47480 \\
(83.4)\end{array}$ & $\begin{array}{c}1.602 \\
(1.586-1.618)\end{array}$ & $\begin{array}{l}1515 \\
(35)\end{array}$ \\
\hline 9 & 1877432 & $\begin{array}{c}1101387 \\
\quad(58.7)\end{array}$ & 624400 & $\begin{array}{c}517998 \\
(83.0)\end{array}$ & 853476 & $\begin{array}{c}635549 \\
(74.5)\end{array}$ & $\begin{array}{c}1.414 \\
(1.409-1.419)\end{array}$ & $\begin{array}{l}734 \\
(17)\end{array}$ \\
\hline 10 & 419724 & $\begin{array}{c}173564 \\
(41.4)\end{array}$ & 187240 & $\begin{array}{c}145737 \\
(77.8)\end{array}$ & 223312 & $\begin{array}{c}165288 \\
(74.0)\end{array}$ & $\begin{array}{c}1.882 \\
(1.869-1.895)\end{array}$ & $\begin{array}{l}1920 \\
(38)\end{array}$ \\
\hline 11 & 498056 & $\begin{array}{c}170078 \\
(34.1)\end{array}$ & 196217 & $\begin{array}{c}116608 \\
(59.4)\end{array}$ & 273144 & $\begin{array}{c}115411 \\
(42.3)\end{array}$ & $\begin{array}{c}1.740 \\
(1.727-1.753)\end{array}$ & $\begin{array}{l}123 \\
(3)\end{array}$ \\
\hline 12 & 268977 & $\begin{array}{c}43859 \\
(16.3)\end{array}$ & 96811 & $\begin{array}{c}33784 \\
(34.9)\end{array}$ & 117783 & $\begin{array}{l}42152 \\
(35.8)\end{array}$ & $\begin{array}{c}2.140 \\
(2.110-2.171)\end{array}$ & 0 \\
\hline Total & 13750968 & $\begin{array}{c}6325401 \\
\quad(46.0)\end{array}$ & 5144236 & $\begin{array}{c}3525773 \\
(68.5)\end{array}$ & 7158316 & $\begin{array}{c}4233451 \\
\quad(59.1)\end{array}$ & $\begin{array}{c}1.490 \\
(1.488-1.492)\end{array}$ & 15754 \\
\hline
\end{tabular}


Figure 1 depicts changes in daily aggregate hand hygiene adherence, plotted against the aggregate hospital COVID-19 census and daily case count across Ontario. Aggregate hand hygiene adherence remained stable until the end of February 2020 , with an average rate of hand hygiene adherence of 46.0\% (6 325401 events of 13750968 opportunities) and a monthly range between $42.5 \%$ and $50.6 \%$. From Mar. 1, 2020, onward, we observed a positive inflection in hand hygiene adherence, which peaked at $79.3 \%$ (66 640 events of 84026 opportunities) on Mar. 30, 2020, before the peak in the Ontario daily COVID-19 case count on Apr. 24, 2020, and the peak in the aggregate COVID-19 inpatient census on Apr. 28, 2020. After this peak, hand hygiene adherence declined steadily until the study end and reached a nadir of $45.5 \%$ (44 193 events of 97164 opportunities) by July 5, 2020.

Figure 2 depicts hand hygiene adherence relative to each hospital's first patient admitted with COVID-19 in March 2020. The absolute hand hygiene adherence was higher on wards than critical care units, but without significant differences in changes over time. Peak hand hygiene adherence was $78 \%$ (67 169 events of 86141 opportunities) by day 20 from the first COVID-19 case, followed by a decline to the nadir of $50.0 \%$ (50 776 events of 101638 opportunities) by day 99 .
Between the first inpatient with COVID-19 and the peak inpatient census, each patient admitted with COVID-19 was associated with improved hand hygiene adherence (IRR 1.0621, 95\% CI 1.0619-1.0623). Increasing Ontario daily case count from start of community transmission to peak was similarly associated with improved hand hygiene (IRR 1.0026, 95\% CI 1.0021-1.0032).

\section{Interpretation}

Using a validated group electronic hand hygiene monitoring system that was implemented across 12 Ontario hospitals, we observed marked practice improvements in hand hygiene that reached nearly $80 \%$ adherence during the first wave of the COVID-19 pandemic. During peak hand hygiene performance rates, this improvement was equivalent to over 10000 additional hand hygiene events per day. These results show that high levels of performance are achievable in a context that enables practice change.

Across most Canadian hospitals, direct observation by auditors continues to be used to measure hand hygiene performance, even though this methodology is recognized to be inaccurate. ${ }^{3-5}$ As a result, reliable reports on hand hygiene performance

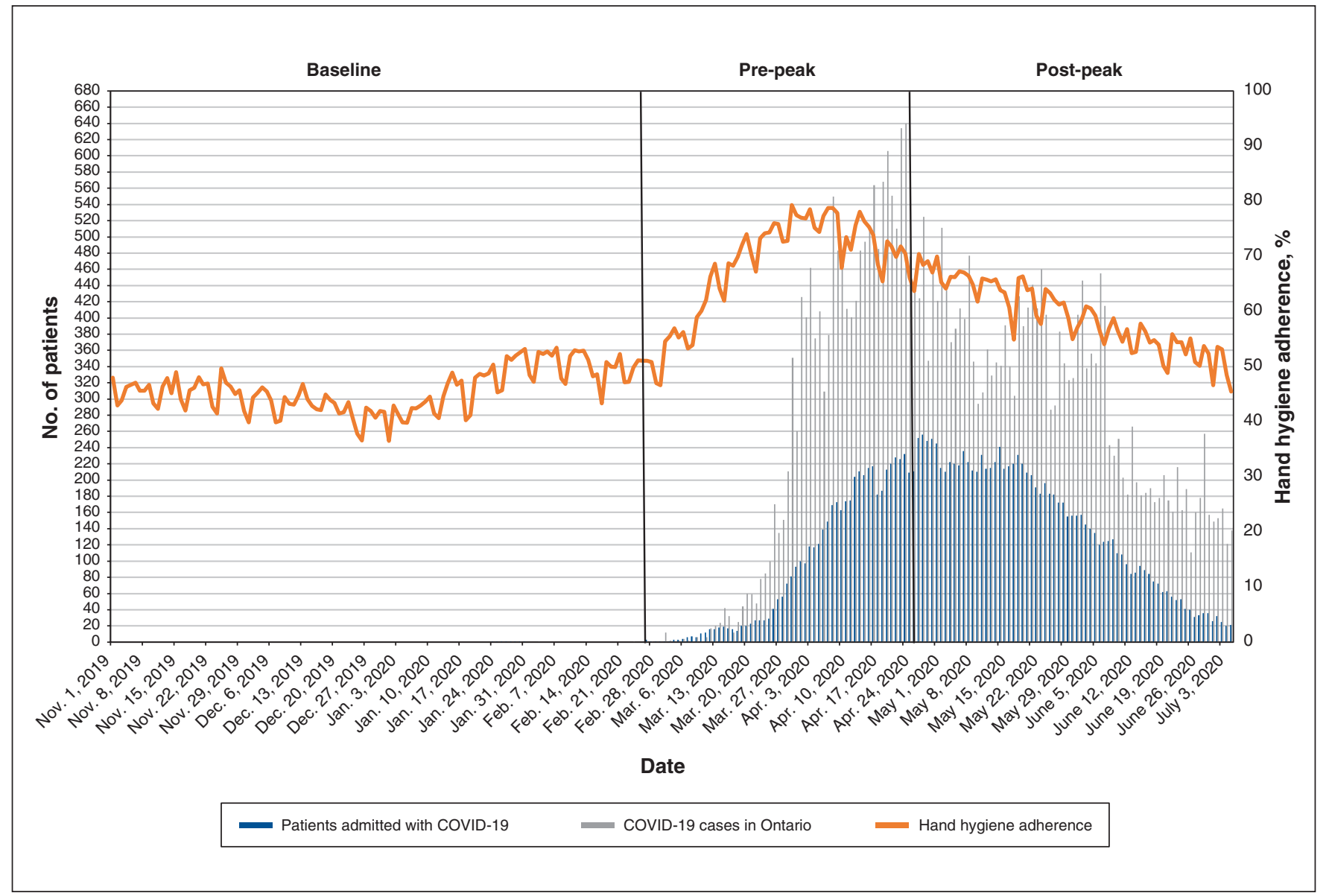

Figure 1: Hand hygiene adherence across 12 acute care hospitals, hospital census of patients with COVID-19 and new daily cases of COVID-19 in Ontario from Nov. 1, 2019, to July 5, 2020, including the pre-peak (Mar. 1 to Apr. 24, 2020) and post-peak (from Apr. 25, 2020, to July 5,2020 ) periods of the first wave of the COVID-19 pandemic in Ontario. 
throughout the pandemic are lacking. The significant improvement we saw using more accurate methodology is consistent with the known enablers of hand hygiene practices. Previous studies have highlighted that health care workers are more likely to clean their hands after contaminating tasks than before critical tasks associated with risk of transmission to others. ${ }^{13,14}$ Infection outbreaks on hospital units have also been shown to be associated with a sharp increase in hand hygiene performance, again, likely because of heightened self-preservation behaviours. ${ }^{15}$

There are 2 notable differences in the improvement in hand hygiene observed with COVID-19 compared to what is observed with other outbreaks. First, the rise in hand hygiene performance was over threefold higher than what has been observed with group electronic hand hygiene monitoring systems during hospital outbreaks unrelated to SARS-CoV-2. ${ }^{15}$ The accentuated improvements in response to SARS-CoV-2, observed in our study and in previous single-centre studies, ${ }^{6,7}$ may be related to the higher degree of fear associated with this novel pathogen, especially early in the pandemic. Second, the improved hand hygiene performance observed in our study was likely associated with the perceived risk of COVID-19 as opposed to the actual risk, since hand hygiene adherence peaked before the highest COVID-19 case numbers.

The factors that most strongly influenced health care worker risk perception can be gleaned from our study. We found a significant association between the number of patients admitted with COVID-19 and hand hygiene practices. This finding suggests that the local experience of health care workers within their hospital influenced practice, either through the tightened infection control protocols of caring for patients with COVID-19 or because of their overall risk perception. The latter may have played a more important role, given the generalized improvement in hand hygiene adherence that we observed, and its association with daily cases of COVID-19 reported across Ontario.

Unfortunately, the improvements in hand hygiene adherence were not sustained across our 12 hospitals as performance returned to baseline levels within 90 days. Most strikingly, this decay in adherence began while COVID-19 case numbers were still increasing. This finding is similar to the single-centre study in the United States that used automated hand hygiene monitoring during the first wave of the pandemic. ${ }^{7}$ We hypothesize that the novelty and perceived risk of caring for patients with COVID-19 most likely decreased over time as health care workers became accustomed to caring for these patients. ${ }^{6,13,15}$ Another potential contributor to this decay in performance is the COVID-19 pandemic itself, which has caused higher levels of health care worker burnout, a situation that is known to contribute to suboptimal hand hygiene rates. ${ }^{16,17}$

Our study has several strengths. It was conducted across a dozen institutions, including both academic and community teaching hospitals. The amount of data collected through

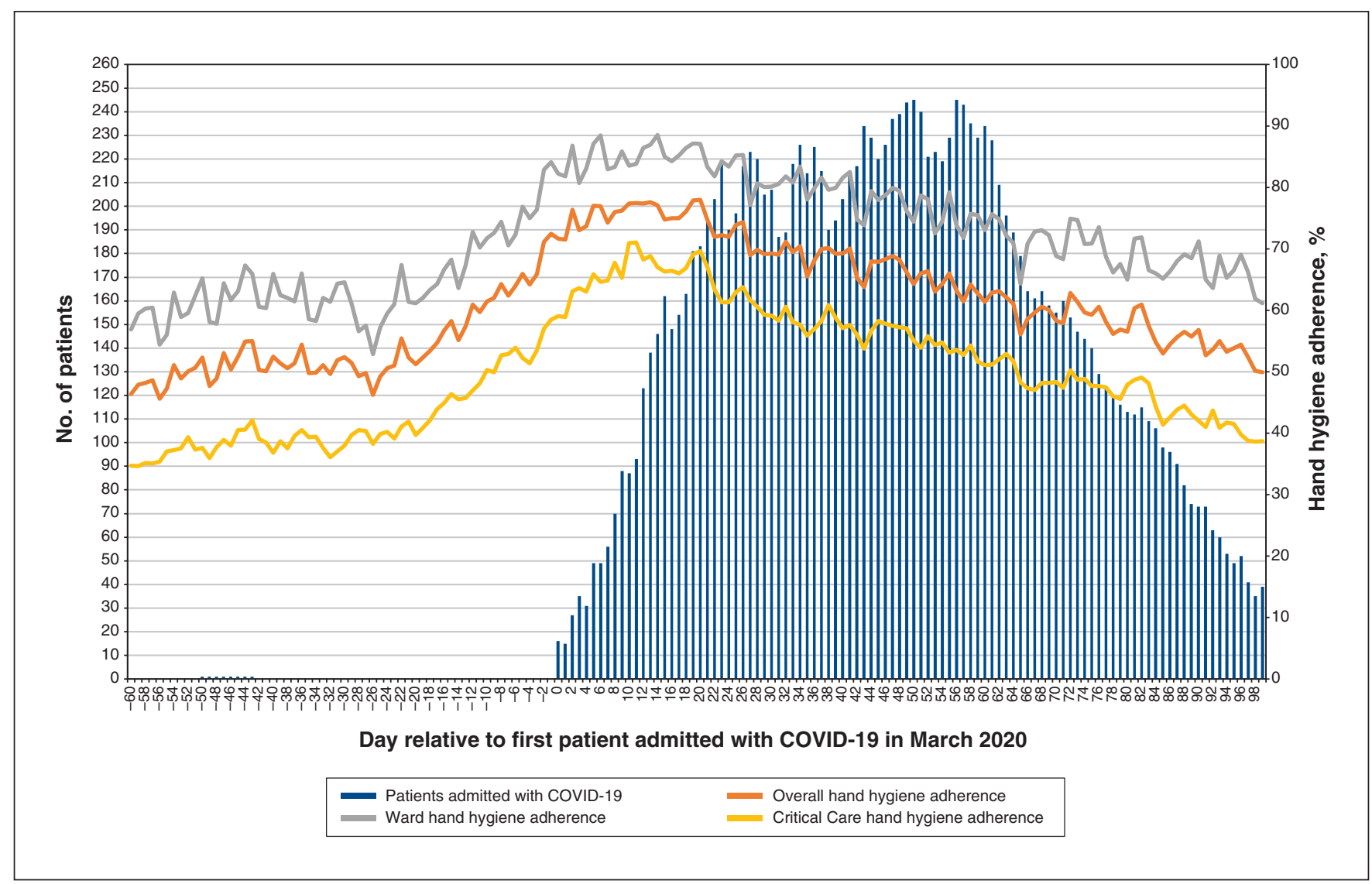

Figure 2: Hand hygiene adherence across 12 acute care hospitals by unit type, relative to each hospital's first admission of a patient with COVID-19 during the first wave of the pandemic in Ontario. 
the group electronic hand hygiene monitoring system is very large, with over 26 million hand hygiene opportunities throughout the study period. Our regression model adjusted for correlation within units, and findings were consistent across both wards and critical care units, which suggests a generalizable behaviour change in response to COVID-19. Our study underscores the importance of adopting more accurate methodology for measuring hand hygiene performance across Canadian hospitals to enable iterative improvement in this important patient safety indicator.

\section{Limitations}

As an observational interrupted time-series study, we cannot fully exclude confounding factors; however, the changes observed are significant and temporally associated with the incidence of COVID-19 during the first wave of the pandemic, which strongly suggests a causal inference. Group electronic hand hygiene monitoring systems provide a unit-level estimate of hand hygiene adherence that cannot differentiate the specific moments of hand hygiene. This is particularly important as the system cannot distinguish whether the rise in adherence was from additional hand hygiene events outside of appropriate moments of hand hygiene. Finally, the study period was limited because of shortages in hand sanitizer that began in July 2020, which limited our ability to assess the impact of further waves of the COVID-19 pandemic on hand hygiene performance.

\section{Conclusion}

The high levels of hand hygiene adherence achieved during the first wave of the COVID-19 pandemic show that substantial improvements in hand hygiene performance are achievable in a context that enables practice change. Health care worker risk perception is a strong enabler of hand hygiene practice changes, but may not reflect actual risk. Future research should seek to determine whether improvement strategies that focus on health care worker perception of personal risk can achieve sustainable improvements in hand hygiene performance.

\section{References}

1. Infection prevention and control during health care when coronavirus disease (COVID-19) is suspected or confirmed [interim guidance]. WHO/2019-nCoV/IPC/2020.4. Geneva: World Health Organization; 2021. Available: https://www.who.int/publications/i/item/WHO-2019-nCoV-IPC -2021.1 (accessed 2021 Feb. 2).

2. Allegranzi B, Pittet D. Role of hand hygiene in healthcare-associated infection prevention. 7 Hosp Infect 2009;73:305-15.

3. Kovacs-Litman A, Wong K, Shojania KG, et al. Do physicians clean their hands? Insights from a covert observational study. 7 Hosp Med 2016;11:862-4.

4. Squires JE, Linklater S, Grimshaw JM, et al. Understanding practice: factors that influence physician hand hygiene compliance. Infect Control Hosp Epidemiol 2014;35:1511-20.

5. Hagel S, Reischke J, Kesselmeier M, et al. Quantifying the Hawthorne effect in hand hygiene compliance through comparing direct observation with automated hand hygiene monitoring. Infect Control Hosp Epidemiol 2015;36:957-62.

6. Huang F, Armando M, Dufau S, et al. COVID-19 outbreak and healthcare worker behavioural change toward hand hygiene practices. 7 Hosp Infect 2021;111:27-34.

7. Makhni S, Umscheid CA, Soo J, et al. Hand hygiene compliance rate during the COVID-19 pandemic. 7AMA Intern Med 2021;181:1006-8.

8. Leis JA, Powis JE, McGeer, et al. Introduction of group electronic monitoring of hand hygiene on inpatient units: a multicenter cluster randomized quality improvement study. Clin Infect Dis 2020;71:e680-5.

9. Leis JA, Obaidallah M, Williams V, et al. Validation and implementation of group electronic hand hygiene monitoring across twenty-four critical care units. Infect Control Hosp Epidemiol 2021 June 25 [Epub ahead of print]. doi: 10.1017/ ice.2021.250
10. STROBE: strengthening the reporting of observational studies in epidemiology. Bern (Switzerland): University of Bern; 2021. Available: https://www. strobe-statement.org/ (accessed 2021 Sept. 20).

11. Nayyar D, Moore C, McCreight L, et al. Hand hygiene opportunities on Canadian acute-care inpatient units: a multicenter observational study. Infect Control Hosp Epidemiol 2018;39:1378-80.

12. Ontario COVID-19 data tool. Toronto: Public Health Ontario. Available: https://www.publichealthontario.ca/en/data-and-analysis/infectious-disease/ covid-19-data-surveillance/covid-19-data-tool? tab=summary (accessed 2021 Sept. 20).

13. Borg MA, Benbachir M, Cookson BD, et al. Self-protection as a driver for hand hygiene among healthcare workers. Infect Control Hosp Epidemiol 2009;30: 578-80.

14. Chang N-CN, Resigner HS, Schweizer ML, et al. Hand hygiene compliance at critical points of care. Clin Infect Dis 2021;72:814-20.

15. Kovacs-Litman A, Muller MP, Powis JE, et al. Association between hospital outbreaks and hand hygiene: insights from electronic monitoring. Clin Infect Dis 2020 Sept. 16 [Epub ahead of print]. doi: 10.1093/cid/ciaa1405.

16. Azoulay E, De Waele J, Ferrer R, et al. ESICM. Symptoms of burnout in intensive care unit specialists facing the COVID-19 outbreak. Ann Intensive Care 2020;10:110.

17. Manomenidis G, Panagopoulou E, Montgomery A. Job burnout reduces hand hygiene compliance among nursing staff. 7 Patient Saf 2019;15:e70-3.

Affiliations: Sunnybrook Health Sciences Centre (Williams, LinkenheldStruk, Leis); Department of Medicine (Kovacs-Litman, Muller, Hota, Powis, Leis), University of Toronto; Division of Infectious Diseases (Muller), St. Michael's Hospital; University Health Network (Hota); Peterborough Regional Health Centre (Powis, Ricciuto), Peterborough, Ont.; Division of Infectious Diseases (Powis), Michael Garron Hospital, Toronto, Ont.; Division of Infectious Diseases (Ricciuto), Lakeridge Health, Oshawa, Ont.; Hamilton Health Sciences (Mertz), Hamilton, Ont.; North York General Hospital (Katz), Toronto, Ont.; Sault Area Hospital (Castellani), Sault Ste Marie, Ont.; Sunnybrook Research Institute (Kiss, Leis), Toronto, Ont.

Contributors: All authors contributed substantially to conception and study design, and to acquisition, analysis and interpretation of data. All authors participated in drafting the manuscript or revising it critically for important intellectual content. All authors provided final approval of the version to be published, and agree to be accountable for all aspects of the work in ensuring that questions related to the accuracy or integrity of any part of the work are appropriately investigated and resolved. Victoria Williams and Adam Kovacs-Litman contributed equally to this study.

Funding: This work was supported by the Innovation Fund of the Funding Plan from the Academic Health Sciences Centres of Ontario at Sunnybrook Health Sciences Centre, St. Michael's Hospital and University Health Network. Support was also received from the Northern Ontario Academic Medicine Association Clinical Innovation Opportunities Fund Award.

Content licence: This is an Open Access article distributed in accordance with the terms of the Creative Commons Attribution (CC BY-NC-ND 4.0) licence, which permits use, distribution and reproduction in any medium, provided that the original publication is properly cited, the use is noncommercial (i.e., research or educational use), and no modifications or adaptations are made. See: https://creativecommons.org/licenses/ by-nc-nd/4.0/

Data sharing: The data set from this study includes only deidentified data, held securely at Sunnybrook Health Sciences Centre. The data may be made available beginning 3 months and ending 5 years after publication to researchers who provide a methodologically sound proposal. Proposals should be directed to the corresponding author. Research ethics board approval and a signed data access agreement are needed to gain access to the data.

Acknowledgements: The authors thank the Infection Prevention and Control teams at each of the 12 participating hospitals for prospective data collection related to COVID-19 admissions.

Disclaimer: The vendor of the group electronic monitoring system played no role in the development of the study protocol, data collection, analysis or interpretation of the results.

Supplemental information: For reviewer comments and the original submission of this manuscript, please see www.cmajopen.ca/content/9/4/ E1175/suppl/DC1. 